ARTIGO ORIGINAL

ISSN 1677-5090

(C) 2014 Revista de Ciências Médicas e Biológicas

\title{
Biocerâmicas e polímero para a regeneração de defeitos ósseos críticos
}

\author{
Bioceramics and polymer for the regenation of bone critical size defects
}

\author{
Iorrana Índira dos Anjos Ribeiro ${ }^{1 *}$, Renata dos Santos Almeida², Daniel Navarro da Rocha ${ }^{3}$, Marcelo \\ Henrique Prado da Silva ${ }^{3}$, Fúlvio Borges Miguel ${ }^{4}$, Fabiana Paim Rosa ${ }^{5}$
}

\begin{abstract}
${ }^{1}$ Nutricionista. Mestranda do Programa de Pós-Graduação Processos Interativos dos Órgãos eSistemas. ICSUFBA; ${ }^{2}$ Bióloga. Mestranda do Programa de Pós-Graduação Processos Interativos dos Órgãos e Sistemas - ICS/ UFBA; ${ }^{3}$ Instituto Militar de Engenharia (IME), Rio de Janeiro, RJ; ${ }^{4}$ Professor Adjunto de Histologia Humana. UFRB.

${ }^{5}$ Professora Adjunto de Patologia - ICS/UFBA
\end{abstract}

\begin{abstract}
Resumo
Introdução: Um grande desafio para a medicina e para os pesquisadores da área de Bioengenharia Tecidual Óssea é desenvolver e aperfeiçoar técnicas e biomateriais que possam devolver a estrutura e funcionalidade do tecido ósseo em situações de perdas ósseas extensas. Objetivo: Avaliar a resposta tecidual após a implantação de biomateriais biocerâmicos: hidroxiapatita (HA) e compósitos, HA associado ao biovidro (Bv) ou ao alginato (alg). Metodologia: Uma amostra de 12 ratos da linhagem Wistar, machos adultos, foram utilizados e distribuídos para a composição de 4 grupos experimentais, avaliados no ponto biológico de 15 dias de pós-operatório: MHA - grupo com defeito preenchido com microesferas de HA; MHABv - grupo com defeito preenchido com microesferas de HA associada ao Bv; MHAalg - grupo com defeito preenchido com microesferas de HA associada ao alg; e Controle - defeito ósseo vazio sem implantação de biomaterial. Resultados: Os grupos MHA e MHAalg apresentaram uma neoformação óssea associada a borda óssea mais evidente que os grupos MHABv e Controle, estes últimos obtiveram uma neoformação restrita a borda do defeito. Em todos os grupos foi observada uma reação inflamatória crônica discreta, a qual nos grupos com implantação de biomaterial foi granulomatosa com a presença de células gigantes multinucleadas. Conclusão: Os biomateriais apresentaram-se como biocompatíveis e osteocondutores. Palavras-chave: Materiais biocompatíveis. Hidroxiapatita. Microesferas.
\end{abstract}

\begin{abstract}
Introduction: A major challenge for medicine and the researchers in the Area of Bone Tissue Bioengineering is to develop and improve techniques and biomaterials that can restore the structure and function of bone tissue in cases of extensive bone loss. Objective: To evaluate the tissue response after implantation of bioceramic biomaterials, to hydroxyapatite (HA); and composites, HA associated with bioglass (Bv) or alginate (alg). Methodology: A sample of 12 Wistar adult male rats were used and distributed for the composition of four experimental groups, evaluated at the biological point of 15 days post-surgery: MHA - group with defect filled with HA microspheres; MHABv - group with defect filled with HA microspheres associated with Bv; MHAalg - group with defect filled with HA microspheres associated with alg; and Control - empty bone defect without implantation of biomaterial. Results: The MHA and MHAalg groups showed a new bone formation associated with more distinctive bony edge than that MHABV and Control groups, the latter obtained a restricted neoformation at the edge of the defect. In all groups a slight chronic inflammatory reaction, which in the groups with implantation of biomaterial was granulomatous with the presence of multinucleated giant cells was observed. Conclusion: The biomaterials showed to be biocompatible and osteoconductive.

Keywords: Biocompatibles Materials. Hydroxyapatite. Microspheres.
\end{abstract}

\section{INTRODUÇÃO}

Os biomateriais são definidos como qualquer material, natural ou sintético, que possa ser usado como arcabouço, de forma temporária ou definitiva, como parte de um sistema que objetiva restaurar ou substituir qualquer tecido, órgão e função do corpo (1). Eles podem ser produzidos a partir de substratos metálicos; poliméricos, naturais ou sintéticos; cerâmicos; ou uma mistura de dois ou mais tipos, denominados compósitos (1).

Algumas propriedades são essenciais aos biomateriais, entre elas a biocompatibilidade, a osteocondução, a osteoindução e a osteogênese. Essas são importantes para

Correspondente / Corresponding: *lorrana Índira dos Anjos Ribeiro. Rua Mello Moraes Filho, 67, Fazenda Grande do Retiro. Salvador, Bahia. CEP: 40350-250. E-mail: indiraanjos@gmail.com que o biomaterial possa integrar-se ao tecido adjacente e neoformado, possa restaurar a estrutura tecidual óssea lesada e, além disso, possa devolver a funcionalidade necessária a esse tecido $(2,3,4)$. Apesar das diversas pesquisas na área da bioengenharia tecidual óssea, ainda não existe um biomaterial ideal para as diversas utilizações clínicas, em especial para os defeitos ósseos críticos (5), o que torna necessário o desenvolvimento de novos biomateriais, bem como o aperfeiçoamento dos já existentes.

A hidroxiapatita (HA) é uma biocerâmica de grande destaque no âmbito científico e clínico, devido à semelhança com a fase inorgânica do tecido ósseo, à sua biocompatibilidade, osteocondutividade e bioatividade $(6,7)$. Contudo, apesar de seu potencial como substituto ósseo, apresenta algumas limitações, como a fragilidade e a lenta reabsorção (8). Uma forma de superar essas limi- 
tações é a sua associação com outros biomateriais, entre os quais se destacam o biovidro (Bv) e o alginato (alg).

O Bv também é uma biocerâmica e se caracteriza por ser biocompatível, osteocondutor e bioativo $(9,10)$. Quando associado à HA, pode melhorar a biodegradação e o seu potencial osteocondutor. Já o alginato é um polímero natural biocompatível, não tóxico, não imunogênico, biodegradável e hidrofílico (11). Sua combinação com a HA tem como principal objetivo mimetizar o tecido ósseo, já que o biomaterial seria composto tanto de um componente orgânico, quanto de um componente inorgânico (12).

Diante disso, o objetivo deste estudo foi avaliar a resposta tecidual após a implantação de biomateriais biocerâmico, a HA, e compósitos, HA/Bv e HA/alg, em formato de microesferas.

\section{METODOLOGIA}

Este experimento foi aprovado pelo Comitê de Ética em Pesquisas no Uso de Animais (CEUA), do Instituto de Ciência da Saúde (ICS), da Universidade Federal da Bahia (UFBA), sob o protocolo no 038/2012.

\section{Amostra}

Foram utilizados 12 ratos da linhagem Wistar, machos adultos, com massa corpórea entre 350 e $400 \mathrm{~g}$ e idade aproximada de 4 a 5 meses, fornecidos, criados e mantidos pelo biotério da Universidade Estadual de Feira de Santana (UEFS). Os animais foram mantidos em caixas de propileno forradas com maravalha autoclavada e receberam ração sólida e água ad libitum, durante todo o experimento.

Os animais foram distribuídos para a composição de 4 grupos experimentais, avaliados no ponto biológico de 15 dias de pós-operatório: MHA - grupo com defeito preenchido com microesferas de hidroxiapatita; MHABV - grupo com defeito preenchido com microesferas de hidroxiapatita associadas ao biovidro; MHAalg - grupo com defeito preenchido com microesferas de hidroxiapatita associadas ao alginato; Controle - defeito ósseo vazio, sem implantação de biomaterial.

Os biomateriais utilizados foram produzidos e cedidos pelo Instituto Militar de Engenharia (IME - RJ).

Procedimento cirúrgico e etapa laboratorial

Previamente à realização do procedimento cirúrgico, os animais foram submetidos à analgesia e sedação com injeção intramuscular de cloridrato de cetamina a $2 \%$, na proporção de $0,1 \mathrm{~mL} / 100 \mathrm{~g}$ de massa corporal, e cloridrato de xilazina a $2 \%$, na proporção de $0,04 \mathrm{~mL} / 100 \mathrm{~g}$ de massa corporal. Em seguida, foram posicionados em decúbito ventral, tricotomizados na região da calvária e submetidos à antissepsia com álcool iodado do campo operatório. Após esta etapa, o acesso cirúrgico à porção mediana da calvária foi obtido com uma incisão cutânea semilunar, com aproximadamente $3 \mathrm{~cm}$ de extensão, mediante a utilização de lâmina de bisturi no 15 , seguida da exposição do periósteo e sua remoção para exposição do tecido ósseo.
Na confecção do defeito ósseo crítico circular transfixado com $8,5 \mathrm{~mm}$ de diâmetro e aproximadamente $0,8 \mathrm{~mm}$ de espessura na porção mediana da calvária, utilizou-se uma fresa trefina com $8 \mathrm{~mm}$ de diâmetro interno, montada em contra-ângulo, com redução de 16:1, acoplada em motor para implante, a 1500rpm, sob irrigação constante com solução fisiológica. Os biomateriais utilizados foram implantados de acordo com cada grupo pré-estabelecido, exceto para o grupo controle, no qual não houve implantação de biomaterial. Em seguida, o retalho foi reposicionado e suturado com pontos interrompidos, com fio de seda 4.0 .

Posterior ao procedimento cirúrgico e de acordo com o ponto biológico de 15 dias de pós-operatório, os animais foram eutanasiados pelo aprofundamento da anestesia e a porção superior da calvária foi removida, com remoção de todo tecido mole. Em seguida, os espécimes foram fixados em formaldeído a 4\%, por 72 horas, e enviados para o processamento histológico. Após a fixação, a calvária foi reduzida, descalcificada, processada e incluída em parafina.

\section{Análise histológica}

Os cortes obtidos foram corados em hematoxilina-eosina (HE), picrossírius red (PIFG) e tricrômico de Goldner (GOLD), e examinados por microscopia de luz comum (Leica DM1000) para observação da resposta tecidual.

\section{RESULTADOS}

Grupo MHA - Microesferas de HA: O biomaterial preencheu tanto a extensão, quanto a espessura do defeito, e organizou-se, em sua maioria, em uma única camada. As microesferas apresentaram grande variação na distribuição de tamanho e pode-se notar o seu deslocamento com maior concentração de microesferas na região de borda. Observou-se uma neoformação óssea associada à borda do defeito, que permeou as microesferas próximas a esta região. A área remanescente do defeito foi preenchida por tecido conjuntivo frouxo, rico em vasos. Uma discreta reação inflamatória crônica granulomatosa foi observada circunjacente às microesferas (Figura 1).

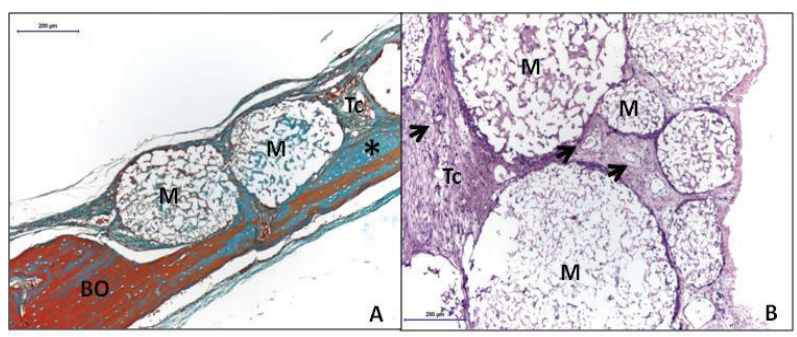

Figura 1 - Grupo $\mathrm{MHA}-15$ dias

(A) Neoformação óssea (*) associada a borda do defeito (BO). Tecido conjuntivo preenchendo a área remanescente (TC). M: microesferas.

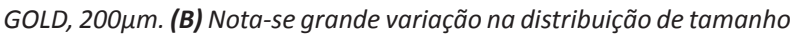
das microesferas (M). Tecido conjuntivo (TC) em permeio ao biomaterial, rico em vasos sanguíneos $(\rightarrow)$. HE, $200 \mu m$.

Fonte: Elaboração dos autores. 
Grupo MHABv - Microesferas de HA associada ao Bv: As microesferas se organizaram em uma única camada e apresentaram, em sua maioria, espessura próxima à espessura da borda do defeito. Pode-se notar uma pequena variação na distribuição de tamanho das microesferas, menor que nos outros grupos. A neoformação óssea, nesse grupo, foi restrita à borda óssea, com preenchimento da área remanescente com tecido conjuntivo mais adensado e rico em vasos sanguíneos. Associado a esse tecido, observou-se uma moderada reação inflamatória crônica granulomatosa, com presença de células gigantes multinucleadas e infiltrado inflamatório linfocitário (Figura 2).

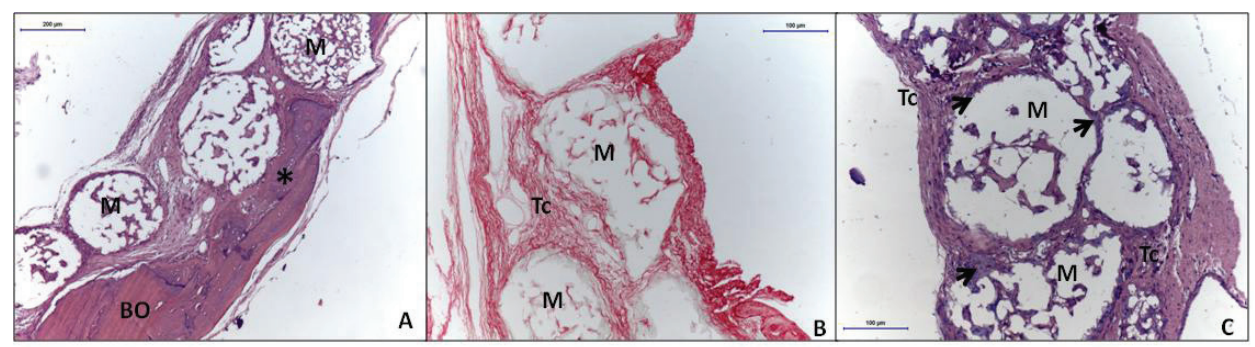

Figura 2 - Grupo MHAalg 15 dias

(A) Observa-se neoformação óssea (*) associada a borda óssea (BO). M: microesferas. HE, 200um. (B) Área central preenchida por um tecido conjuntivo (Tc) mais adensado em permeio às microesferas de HAalg (M). PIFG, 100 $\mu$ m. (C) Reação inflamatória crônica granulomatosa mais evidente, caracterizada pela presença de células gigantes multinucleadas $(\rightarrow)$ ao redor das microesferas (M). Tc: tecido conjuntivo. HE, $100 \mu m$.

Fonte: Elaboração dos autores

Grupo MHAalg - Microesferas de HA associada ao alg: $O$ defeito foi totalmente preenchido pelas microesferas de HAalg. Elas se organizaram com uma ou duas camadas. Notou-se uma neoformação óssea mais evidente em permeio às microesferas próximas à borda. $O$ tecido conjuntivo organizado se formou de modo circunjacente às microesferas, associado à inflamação crônica granulomatosa discreta e vasos sanguíneos (Figura 3).

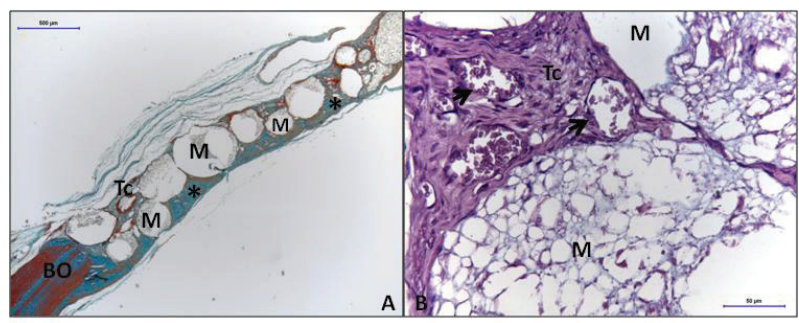

Figura 3-Grupo MHABv - 15 dias

(A) Neoformação óssea (*) mais evidente com crescimento centrípeto e em permeio as microesferas (M). BO: borda óssea. Tc: tecido conjuntivo. GOLD, 500um. (B) Tecido conjuntivo (TC) mais adensado em permeio as microesferas (M) na região central do defeito, com presença de vasos sanguíneos $(\rightarrow)$. HE, 50 $\mu m$.

Fonte: Elaboração dos autores.

Grupo Controle: $\mathrm{O}$ grupo controle teve seu defeito preenchido por tecido conjuntivo frouxo delgado, bem vascularizado, e neoformação óssea restrita às bordas do defeito. Observou-se também a presença de inflamação crônica, que se caracterizou pela presença de um infiltrado inflamatório linfocitário difuso (Figura 4).

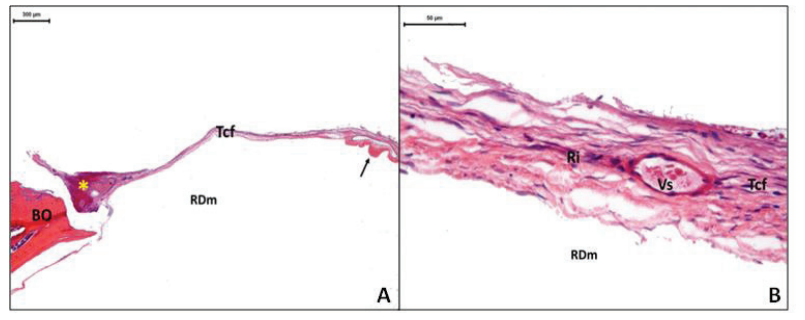

Figura 4-Grupo Controle - 15 dias

(A) Neoformação óssea restrita a borda do defeito (*). Área remanescente preenchida por tecido conjuntivo (Tcf). BO - borda óssea, $R D m$ - região da dura-mater, $(\rightarrow)$ Veia central. $H E, 300 \mu m$. (B) Reação inflamatória crônica (Ri) associada ao tecido conjuntivo (Tcf). Presença de vasos sanguíneos (Vs). HE, $50 \mu \mathrm{m}$.

Fonte: Elaboração dos autores.

\section{DISCUSSÃO}

Um fator importante que interfere sobre a formação de um interstício adequado e, subsequentemente, na resposta tecidual ao biomaterial é o formato com que este se apresenta. Nesse aspecto, o formato de microesferas, utilizado neste estudo, apresenta grande vantagem de aplicação, já que favorece a formação de um interstício que possibilita a difusão de micronutrientes e fatores de crescimento, favorece a migração, proliferação e diferenciação celular, além de angiogênese (13). Esta última é um fenômeno fundamental para a finalização dos mecanismos biológicos regenerativos (14) e foi observada nos grupos MHA e MHABv que mostraram grande potencial angiogênico.

Associada ao formato, a variação de tamanho das microesferas também atua diretamente sobre a resposta 
tecidual, uma vez que acredita-se que as partículas com tamanho regular propiciam a formação de um interstício adequado para promoção da diferenciação de células ao longo do defeito, bem como uma adequada neoformação vascular (15-18). Entretanto, neste estudo, as microesferas que tiveram maior variação de distribuição de tamanho, como MHA e MHAalg, apresentaram melhor potencial osteocondutor.

A composição dos biomateriais, bem como suas propriedades físico-químicas, também influenciou na resposta observada. A composição química da HA tem grande semelhança com o componente mineral ósseo e, além disso, ela é biocompatível e osteocondutora (7), propriedades observadas nos resultados deste estudo. Barreto (19), ao avaliar biomaterial semelhante ao utilizado neste trabalho - microesferas de HA -, obteve resultados parecidos, porém com uma neoformação óssea discreta restrita à borda do defeito.

$O$ alginato, quando em contato com cátions divalentes, tem a propriedade de formar hidrogéis (20). A formação de hidrogel pode ter favorecido o menor deslocamento das microesferas de HAalg quando comparado aos outros grupos. Isso garante a presença de um arcabouço em toda a extensão da área lesada, característica muito importante para a regeneração do defeito. Ademais, esses hidrogéis têm propriedades macromoleculares similares à MEC (20), o que aumenta a semelhança do biomaterial com a matriz óssea, já que ele apresenta um componente inorgânico e um componente orgânico em sua composição. Essas características podem ter favorecido a neoformação óssea associada à borda óssea mais evidente no grupo MHAalg. Esses resultados corroboram os resultados encontrados por Paula e colaboradores (21) e Rolim (22) que também observaram uma neoformação óssea mais acentuada, aos 15 dias, no grupo de microesferas de HAalg. Contudo, trabalho anterior de Ribeiro (15) obteve uma neoformação óssea limitada às bordas no grupo das microesferas de HA, aos 15 dias. Essas distinções podem estar relacionadas a possíveis diferenças nas propriedades físico-químicas entre os biomateriais, como superfície, porosidade, entre outras.

A ausência de um arcabouço que favoreça a migração de células osteogênicas e a proliferação vascular até a região central do defeito propicia o preenchimento de sua extensão por um tecido conjuntivo delgado e uma neoformação óssea limitada, restrita às bordas. Esta neoformação ocorre pelos estímulos locais produzidos pelo próprio ato cirúrgico, como a ruptura vascular, deslocamento do periósteo e a reação inflamatória local que favorece a liberação de citocinas (23). Essas características, próprias de um defeito crítico, foram observadas no grupo controle aqui empregado, e corroboram com os resultados anteriores encontrados pelos mesmos autores deste estudo $(5,15,19,24-27)$ e de outros autores (28-30).

Apesar de a bioatividade ser uma das principais características do Bv e estar intimamente relacionada ao processo de regeneração, a neoformação óssea observada nesse grupo foi semelhante ao do grupo controle, limitada às bordas. Contudo, vale ressaltar que a resposta tecidual ao Bv irá variar em função da sua composição e relação com seus constituintes (26), o que torna imprescindível a caracterização físico-química desse biomaterial.

Este estudo avaliou os biomateriais numa fase inicial do reparo (15 dias), momento no qual se avaliaram reações teciduais importantes, como a reação inflamatória, fator crucial ao prosseguimento dos estudos com o biomaterial, já que para ser considerado biocompatível ele não deve promover uma reação imunológica ou inflamatória exacerbada e prejudicial ao tecido adjacente (31). O Bv quando em contato com fluídos biológicos suscita diversas reações químicas que desencadeiam dissolução e formação de uma camada de hidroxicarbonato apatita (26). Essas reações podem ter sido responsáveis pela reação inflamatória mais evidente no grupo de HABv.

Cabe salientar que novos estudos devem ser realizados com pontos biológicos maiores, com o intuito de evidenciar tanto a evolução da resposta desses biomateriais, como o aperfeiçoamento em suas propriedades físico-químicas, principalmente quanto à variação na distribuição de tamanho das microesferas, a fim de avaliar se essas modificações interferirão na resposta tecidual ao biomaterial.

\section{CONCLUSÕES}

Os biomateriais avaliados neste estudo demonstraram ser biocompatíveis e osteocondutores - microesferas de hidroxiapatita, microesferas de hidroxiapatita associadas ao alginato e as microesferas de hidroxiapatita associadas ao biovidro, respectivamente. A presença do biovidro na composição das microesferas de hidroxiapatita não favoreceu melhor comportamento osteogênico desse biomaterial.

\section{REFERÊNCIAS}

1. LAVIK, E.; LANGER, R. Tissue engineering: current state and perspectives. Appl. Microbiol. Biotechnol., Berlin, v. 65, n. 1, p. 1-8, 2004.

2. AMINI, A. R.; LAURENCIN, C. T.; NUKAVARAPU, S. P. Bone tissue engineering: recent advances and challenges. Crit. Rev. Biomed. Eng., Boca Raton, v. 40, n. 5, p. 363-408, 2012.

3. BHATT, R. A.; ROZENTAL, T. D. Bone Graft Substitutes. Hand. Clin., Philadelphia, v. 28, n. 4, p. 457-468, 2012

4. CATAURO, M. et al. Synthesis of $\mathrm{SiO} 2$ and $\mathrm{CaO}$ rich calcium silicate systems via sol-gel process: bioactivity, biocompatibility, and drug delivery tests. J. Biomed. Mater. Res. Part A, Hoboken, v. 102, n. 9, p. 3087-3092, 2013.

5. ROLIM, A. E. H. Estudo in vivo de materiais biomiméticos, associados ou não à administração enteral de estrôncio, para o reparo de defeito ósseo. 2013. 215 f. Tese (Doutorado em Processos Interativos dos Órgãos e Sistemas) - Instituto de Ciências da Saúde, Universidade Federal da Bahia, Salvador, 2013.

6. MOREIRA, A. S. B.; PASTORELI, M. T.; DAMASCENO, L. H. F. Estudo experimental da influência das dimensões dos grânulos de hidroxiapatita na integração óssea. Acta Ortop. Bras., São Paulo, v. 11, n. 4, p. 240-250, 2003 
7. WOODARD, J. R. et al. The mechanical properties and osteoconductivity of hydroxyapatite bone scaffolds with multi-scale porosity. Biomaterials, Guildford, v. 28, n. 1, p. 45-54, 2007.

8. BENAQQA, C. et al. Slow crack growth behaviour of hydroxyapatite ceramics. Biomaterials, Guildford, v. 26, n. 31, p. 6106-6112, 2005.

9. LIANG, W. et al. Bioactive borate glass scaffold for bone tissue engineering. J. Non-Cryst. Solids, [S. I.], v. 354, n. 15-16, p. 1690-1696, 2008.

10. LIMA, C. J. et al. Resposta do tecido subcutâneo de camundongos à implantação de um novo biovidro à base de óxido de nióbio. Matéria, Rio de Janeiro, v. 16, n. 1, p. 574-582, 2011.

11. AUGST, A. D.; KONG, H. J.; MOONEY, D. J. Alginate hydrogels as biomaterials. Macromol. Biosci., Weinheim, v. 6, n. 8, p. 623-633, 2006.

12. RIBEIRO, C. C.; BARRIAS, C. C.; BARBOSA, M. A. Calcium phosphate-alginate microspheres as enzyme delivery matrices. Biomaterials, Guildford, v. 25, n. 18, p. 4363-4373, 2004.

13. Al-AQL, Z. S. et al. Molecular mechanisms controlling bone formation during fracture healing and distraction osteogenesis. J. Dent. Res., Washington, v. 87, n. 2, p. 107-118, fev. 2008.

14. MIGUEL, F. B. Avaliação do potencial osteogênico de matrizes tridimensionais colagênicas aniônicas, reticuladas ou não em glutaraldeído, na regeneração de defeitos críticos, em calvária de rato. 2008. 158f. Tese (Doutorado em Patologia Humana) - Faculdade de Medicina, Universidade Federal da Bahia; Centro de Pesquisa Gonçalo Moniz, Fundação Oswaldo Cruz, Salvador, 2008.

15. RIBEIRO, I. I. A. Estudo da implantação in vivo de biomateriais compósitos de fosfato de cálcio e polímero. Salvador, 2013. 78 f. Dissertação (Mestrado em Processos Interativos dos Órgãos e Sistemas) - Instituto de Ciências da Saúde, Universidade Federal da Bahia, Salvador, 2013.

16. SCHEPERS, E. J. et al. Bioactive glass particles of narrow size range: a new material for the repair of bone defects. Implant Dent., Baltimore, v. 2, n. 3, p. 151-156, 1993.

17. MARCACCI, M. Stem cells associated with macroporous bioceramics for long bone repair: 6- to 7-year outcome of a pilot clinical study. Tissue Eng., New York, v. 13, n. 5, p. 947-955, 2007.

18. TIAN, M. et al. In vivo study of porous strontium-doped calcium polyphosphate scaffolds for bone substitute applications. J. Mater. Sci. Mater. Med., London, v. 20, n. 7, p.1505-1512, 2009.

19. BARRETO, I. C. Utilização de microesferas de hidroxiapatita no reparo de defeitos críticos em calvária de rato. 2008. 104 f. Dissertação (Mestrado em Ciências Morfológicas) - Instituto de Ciências Biomédicas, Universidade Federal do Rio de Janeiro; Instituto de Ciências da Saúde, Universidade Federal da Bahia, Salvador, 2008.

20. YANG, J.; XIE, Y.; HE, W. Research progress on chemical modification of alginate: a review. Carbohydr. Polym., United Kingdom, v. 84, n. 1, p. 33-39, 2011.
21. PAULA, F. L. et al. Hidroxyapatite-alginate biocomposite promotes bone mineralization in different lenght scales in vivo. Front. Mater. Sci. China, Beijing, v. 3, n. 2, p. 145-153, 2009.

22. ROLIM, A. E. H. Avaliação de microesferas de hidroxiapatita, dopadas ou não com estrôncio, no reparo de defeito ósseo crítico, em calvária de rato. 2010. 91 f. Dissertação (Mestrado em Clínica Odontológica) - Faculdade de Odontologia, Universidade Federal da Bahia, Salvador, 2010.

23. ANDERSON, J. M.; RODRIGUEZ, A.; CHANG, D. T. Foreign body reaction to biomaterials. Semin. in Immunol., Philadelphia, v. 20, n. 2, p. 86-100, 2008.

24. BARRETO, I. C. Utilização de ranelato de estrôncio associado a biometrias para regeneração óssea. 2011. 176f. Tese (Doutorado em Processos Interativos dos Órgãos e Sistemas) - Instituto de Ciências da Saúde, Universidade Federal da Bahia, Salvador, 2011.

25. CARVALHO, A. A. Reparo ósseo de defeito crítico em calvária de rato com microesferas de hidroxiapatita e selante de fibrina. 2010. 120 f. Dissertação (Mestrado em Processos Interativos dos Órgãos e Sistemas)- Universidade Federal da Bahia, Instituto de Ciências da Saúde, Salvador, 2010.

26. ALMEIDA, R. S. Avaliação da implantação de grânulos de $\beta$-TCP associado ou não à biovidro fosfatado para regeneração de defeito ósseo. 2013. 82f. 2013. Dissertação (Mestrado em Processos Interativos dos Órgãos e Sistemas) - Instituto de Ciências da Saúde, Universidade Federal da Bahia, Salvador, 2013.

27. MIGUEL, F. B. et al. Regeneration of critical bone defects with anionic collagen matrix as scaffolds. J. Mater. Sci., Mater. Med., London, v. 24, n.11, p. 2567-2575, nov. 2013.

28. PARK, J. W. et al. Bone formation with various bone graft substitutes in critical sized rat calvarial defect. Clin. Oral Implant. Res., Copenhagen, v. 20, n. 4, p. 372-378, 2009.

29. ACCORSI-MENDONÇA, T. et al. Biological monitoring of a xenomaterial for grafting: an evaluation in critical-size calvarial defects. J. Mater. Sci. Mater. Med., London, v. 22, n. 4, p. 997-1004, abr. 2011.

30. CONZ, M. B.; GRANJEIRO, J. M.; SOARES, G. A. Hydroxyapatite crystallinity does not affect the repair of critical size bone defects. J. Appl. Oral Sci., Bauru, v. 19, n. 4, p. 337-342, 2011.

31. GARG, T. et al. Scaffold: a novel carrier for cell and drug delivery. Crit. Rev. Ther. Drug Carrier Syst., Boca Raton, v. 29, n. 1, p. 1-63, 2012.

32. BIANCON FILHO, L. A. et al. Evaluation of optical density of bone defects filled with calcium phosphate cement and bioactive glass in rats. Acta Cir. Bras., Salvador, v. 26, n. 1, p. 2-6, 2011.

33. KLENKE, F. M. et al. Impact of pore size on the vascularization and osseointegration of ceramic bone substitutes in vivo. J. Biomed. Mater. Res. Part A, Hoboken, v. 85, n. 3, p. 777-786, 2008.

Submetido em: 6/10/2014

Aceito em: 15/12/2014 